
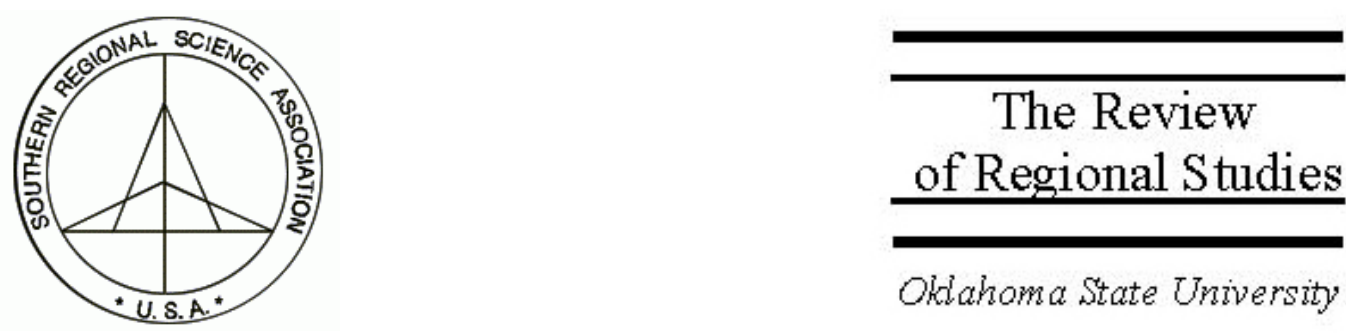

Oklahoma State University

\title{
Is the “Cost of Enough Food” Lower in Rural Areas?
}

\author{
Mark Nord
}

Economic Research Service, USDA, 1800 M St NW, Room 2180, Washington, D.C. 20036-5831, e-mail: marknord@ers.usda.gov

Ephraim Leibtag

Economic Research Service, USDA, 1800 M St NW, Room 2124, Washington, D.C. 20036-5831, e-mail: eleibtag@ers.usda.gov

\begin{abstract}
We develop and assess two inter-area cost-of-enough-food indices using nationally representative data from the Current Population Survey Food Security Supplements on how much households say they would need to spend to just meet their food needs. We calculate the indices for 470 geographic areas identified by state, specific metropolitan statistical area (or nonmetropolitan), and central-city/balance-MSA residence. On average, the cost-of-enough-food is between 11 and 14 percent less for nonmetropolitan households than for otherwise similar metropolitan households. These findings suggest that differences in poverty rates generally overstate differences in material hardship experienced by households in rural areas versus urban areas.
\end{abstract}

Keywords: Cost of food; Cost of living; Rural-urban; Inter-area cost of living

JEL classification: $I ; R$

The views expressed here are those of the authors, and may not be attributed to the Economic Research Service of the U.S. Department of Agriculture. 


\section{INTRODUCTION}

The use of poverty rates to compare the extent of economic hardship among regions and across the rural-urban continuum is problematic because the official poverty thresholds are uniform nationwide, while the costs of living vary among regions and between rural and urban areas. Comparisons of poverty rates, therefore, overstate the extent of economic hardship in low-cost-of-living areas compared with high-cost-of-living areas. Although there is general agreement that it would be desirable to adjust the poverty thresholds for inter-area differences in the cost of living, an adequate base of official statistics to support a credible and geographically comprehensive adjustment does not exist at present (Citro and Michael 1995).

The implications for research on rural well-being of inter-area differences in costs of living are considerable. Income measures and poverty rates are widely used to compare the well-being and the extent of economic hardship between rural and urban areas. These measures generally indicate a lower level of economic well-being and a greater prevalence of economic hardship among rural residents than among their urban counterparts (Hamrick 2005; Beale 2004; Jolliffe 2003). However, most or all of these differences could reflect rural-urban differences in the costs of living rather than true differences in well-being (Nord 2000; Nord and Cook 1995).

Research by a National Academy of Sciences (NAS) panel, appointed to recommend improvements to the official poverty measure, found that the cost of housing was lower, on average, in rural than in urban areas (Citro and Michael 1995). Nord (2000) found that inter-area differences in the association of income with food insecurity (i.e., difficulties households face in accessing enough food) implied a substantially lower cost of living in nonmetropolitan areas than in metropolitan statistical areas.

In this paper, we examine inter-area differences in the amount of money low-income households reported needing to spend to meet their food needs. Food purchases are the second largest share of the budgets of most low-income households, following housing. Adjusting income and poverty comparisons for differences in the costs of both housing and food would correct a substantial proportion of the cost-of-living bias in these comparisons.

We first examine data from the Current Population Survey Food Security Supplement (CPS-FSS) on households' usual food spending and the minimum amount they report needing to spend to just meet their food needs. We assess the relationship, at the national level, of these food spending amounts with income. We then use these data to calculate two indices of the cost of "enough food" across various geographic and metropolitan residence categories. We compare these indices between metropolitan (metro) and nonmetropolitan (nonmetro) areas at the national level for each Census Region, each Census Division, and each state. 
The indices described in this paper are not food price indices. Although they share some characteristics of food price indices as applied to estimating costs of living for comparing welfare across markets or over time, they also differ from price indices in important ways. A cost-of-living index attempts to estimate the minimum expenditure required to achieve a given level of welfare (utility or standard-of-living) across two different markets or time periods. This requires, at the most fundamental level, a clear definition of each good or service in question, a clear and consistent understanding of what the price of that good or service entails, and a weighting scheme to aggregate the prices of the of set of goods and services to a single overall cost (Hill 2004; Fisher 1927).

The indices developed in this study might most appropriately be described as "costof-enough-food" indices. They are based on the amounts households reported needing to spend to just meet their food needs. (The amounts are adjusted for household size and, in the case of one index, for household-level differences in income.) In providing this single overall cost, the respondent implicitly integrates information on both prices and the composition of the market basket required to achieve this level of utility. (See Berndt et al. 1998 for a related approach in the medical sector.)

The cost-of-enough-food approach avoids one of the perennial problems of price indices as measures of cost of living - how to deal with differences in the composition of the market basket. Comparisons of price-index-based costs of living can be biased if the shares of the components of an index differ across markets or change over time due either to differences in preferences or to differences in the relative prices of components. In the latter case, consumers may respond to the price differences by changing the shares of the components in their expenditure patterns with the result that the difference in the index overstates the difference in utility. The cost-of-enough-food index implicitly adjusts for these compositional differences by relating the cost estimate directly to the utility standard of "just enough food to meet the needs of your household."

A potential weakness of the cost-of-enough-food indices, however, is that they may reflect inter-area differences in socially formed expectations of what an adequate diet comprises (i.e., what is "enough food") and thus be based on different utility standards. A cost-of-enough-food index will reflect inter-area differences between nominal food spending and physiological food well-being, provided that the physiological well-being represented by the normative diet (i.e., what respondents think of as "enough food") is the same across geographic regions. The extent to which this condition of equivalence is met cannot be assessed using the CPS-FSS data. Even if this standard of equivalence is not met, however, a cost-of-enough-food index will adjust food spending to indicate inter-area differences in subjective food well-being. This standard of equivalence is consistent with the concept of poverty as the inability to participate fully and without shame in the local society and may be an appropriate basis of comparison for many analytic purposes. 


\section{PREVIOUS FINDINGS ON INTER-AREA DIFFERENCES IN COSTS OF LIVING AND FOOD PRICES}

There is general agreement that adjusting the poverty thresholds for geographic differences in costs of living would improve their representation of inter-area differences in economic hardship. Lack of such adjustment is one of the most frequent and serious criticisms of the current poverty measure both by social researchers and by policy officials. However, serious attempts to develop such adjustments have consistently concluded that adequate official data to make a defensible, comprehensive geographic adjustment do not presently exist (Citro and Michael 1995; Economic Research Service 1976; Government Accounting Office 1995). Official statistics on inter-area differences in costs of living have not been published since the termination of the Bureau of Labor Statistics' "Family Budgets" series in 1981, and that series did not include rural areas.

In the early 1990s, an NAS panel proposed a thorough overhaul of the poverty measure. Recognizing the importance and the formidable problems of adjusting the poverty rate for geographic differences in the cost of living, the panel proposed that research should be initiated to support an adequate adjustment (Citro and Michael 1995). Until such research was completed, the panel recommended that a partial adjustment of the poverty thresholds be made for geographic differences in costs of housing, since variation in housing cost is the largest component of geographic variation in cost of living and adequate inter-area housing cost data are available. The proposed housing cost index, based on decennial census data on costs for specified quality of housing, was lower in nonmetro than in metro areas in every Census Division.

Research by Nord (2000) estimated cost-of-living differences across regions and along the rural-urban continuum using food security data from the CPS-FSS to equate levels of well-being across areas. At the national level, the cost of living in nonmetro areas was estimated to be 16 percent lower than that in metro areas. Furthermore, in every Census Division, the nonmetro cost of living was below that for metro areas.

Findings from store-based research on food prices are inconsistent as to whether there are any systematic difference in food prices among neighborhoods with respect either to income or rurality. Recent work by King, Leibtag, and Behl (2004) implies that retail food prices may be lower in nonmetro areas than in metro areas. They compared store operating costs and characteristics of stores in metro and nonmetro areas and categorized stores based on the percentages of their sales that come from Food Stamp redemptions to identify stores in which high proportions of low-income households shopped. They found significant differences in the operating costs and characteristics of food stores from which low-income households purchase their food products in metro and nonmetro areas. All else being equal, to the extent that lower gross margins (sales revenue less operating costs) in nonmetro areas result in lower food prices, the observed differences imply that, on average, food prices faced by low-income households may be lower in nonmetro than in metro areas. 
Much of the available research information on rural-urban and other inter-area differences in the cost of food has been a byproduct of research on the question of whether the poor face lower or higher prices due to where they shop for food. Evidence summarized by Kaufman et al. (1997) from 14 store surveys conducted between 1966 and 1996 indicates that food prices were generally higher in smaller grocery stores than in larger supermarkets and also higher in inner city and rural locations than in suburban locations. Since the poor are more likely to shop in small grocery stores and to live in inner city or rural locations, they often do face higher food prices. On average, food prices were found to be 3.1 percent higher in rural low-income areas than in urban low-income areas. Furthermore, evidence from food stamp redemption rates suggested that compared with low-income urban residents, low-income rural residents purchased a considerably larger proportion of their food in smaller stores rather than in supermarkets, implying that the 3.1 percent average food price differential would understate the difference in food prices.

Findings from two studies published since the Kaufman et al. (1997) summary are consistent with the earlier results, but findings from a third study are not. These studies all differentiated areas based on the prevalence of low income, however, not on ruralurban residence. Chung and Myers (1999) concluded that the poor faced higher food prices primarily because of limited access to larger stores with greater variety of products. Frankel and Gould (2001) also found that low-income households faced higher food prices and that the prices they faced depended on their proximity to low- and middle-income neighborhoods. On the other hand, Hayes (2000) found that food prices were significantly lower in poor neighborhoods. However, Hayes' analysis was based on only five homogeneous products and failed to account for item availability, which may bias price differentials upward.

Findings from household-level analyses are similarly inconsistent. Low-income households in the U.S. Department of Agriculture's Nationwide Food Consumption Survey (NFCS) were found to have faced lower unit costs for almost every major food group (Kaufman et al. 1997). This appeared to result from economizing strategies that low-income households used to keep food costs low. Analysis of household-based scanner data for a national sample of 40,000 households confirmed the importance of these economizing strategies (Leibtag and Kaufman 2003). Low-income households were found to economize by purchasing random-weight products on sale, purchasing a greater proportion of private-label products, and purchasing less expensive meats, fruits, and vegetables. By using these strategies, low-income households were able to spend less per unit for these general categories of food despite facing the slightly higher prices that other studies have shown to exist.

These findings are offset somewhat by conclusions from a study by Finke, Chern, and Fox (1997) using the same (NFCS) data. Unit food costs for nine relatively homogeneous food categories were significantly higher for urban households than for suburban households. Rural households were not included in the sample, but the results suggest that economizing strategies did not fully offset the effect of higher prices charged in the stores where many low-income households purchase their food. This conclusion is, 
however, somewhat weakened because the specific food items analyzed in this study are generally not branded, which makes it more difficult to economize except on package size.

Davis and Leibtag (2004) used scanner data to estimate food price differences across 17 markets in the U.S. and found substantial variation in average food prices across markets. However, for the selected WIC package food items analyzed, there were no large or systematic differences in average prices paid between income groups within a given market. This suggests that interstate price differences play a more important role in the differences in food costs between low-income and high-income households than do differences that exist across income groups within a given state.

In summary, research findings on food prices faced by the poor are inconsistent and shed relatively little light on food prices faced by rural versus urban households. Some studies suggest that households in rural areas may, on average, face somewhat lower food prices than households in suburban areas. Others suggest that the rural households may face higher food prices - primarily because a larger proportion of their food is purchased in smaller stores - but may partially or completely offset these higher prices by various economizing strategies. There is, however, little research using nationally representative data that brings these factors together along with food and diet expectations in order to compare the costs of meeting household food needs across geographic space and across the rural-urban continuum.

\section{DATA AND METHODS}

Data on household food expenditures, household income, and how much households report they would need to spend for food to meet their food needs were taken from the Current Population Survey Food Security Supplements (CPS-FSS) of September 2000, April 2001, December 2001, and December 2002. The CPS is a monthly survey of about 60,000 households conducted by the Census Bureau for the Bureau of Labor Statistics. It is the federal government's primary source of information on the labor force and employment characteristics of the U.S. population. The sample is representative of the U.S. civilian non-institutional population. The core questionnaire obtains information on household composition and income as well as demographic information for all household members and employment status of each member of the household 15 years of age and older. Supplemental questions are added to the core CPS questionnaire from time to time to produce estimates on a variety of topics. The CPS-FSS, sponsored annually by USDA, obtains information on households' food spending, food program participation, and food security.

The data used for this study were collected in the CPS-FSS using the following protocol.

- Household respondents were first asked whether, during the past week, anyone in the household had bought food in each of four kinds of places-(1) supermarkets or grocery stores; (2) meat markets, produce stands, bakeries, warehouse clubs, and 
convenience stores; (3) restaurants, fast food places, cafeterias, or vending machines; and (4) "any other kind of place."

- After these four questions, a second set of questions asked how much they spent for food during the week (including amounts paid with food stamps) in each kind of place in which they reported buying food. Amounts spent for nonfood items were reported and subtracted from the total.

- The total food spending for the previous week was reported back to the respondents and they were asked how much they usually spent for food in a week.

- They were then asked, "In order to buy just enough food to meet the needs of your household, would you need to spend more than you do now or could you spend less?" If they said "more" they were then asked how much more. If they said "less" they were asked how much less. If they said "the same" (which was not presented as a response option, but was accepted if volunteered), no follow-up was asked.

\subsection{Household-Level Food Spending and Minimum-Needed Food Spending}

We calculated the minimum-needed weekly food spending for each household as their reported usual food spending plus or minus the amount more or less that they reported they would need to spend. We then annualized this weekly value and divided the annualized value by the household's annual poverty threshold to norm for household size and age composition. Poverty thresholds were calculated for each household based on the numbers of adults and children and the age of the reference person (elderly/ nonelderly), following the standard Census Bureau specifications. Similarly, we calculated each household's usual food spending as a ratio to the household's poverty threshold.

A possible problem with the use of households' reported minimum-needed food spending as a measure of food cost is that minimum food expectations almost certainly depend to some extent on income. Higher-income households are likely to have higher expectations of what constitutes a minimally acceptable diet. We anticipated, therefore, that the sample for estimating food costs in a geographic area would have to be restricted to households within some low-income range, and that it might be necessary to adjust the measure for household income. To assess the seriousness of this problem and identify an appropriate income range for the estimation sample, we classified households in narrow income ranges based on their annual income (using "control card income" HUFAMINC, and norming for household size and composition by dividing annual income by the household's poverty threshold). Mean and median "minimum-needed food spending" 
were calculated within each income range. ${ }^{1}$ Minimum-needed food spending, as measured by the mean within each income range, was nearly constant at about 30 to 33 percent of the poverty line for households with incomes up to about three times the poverty line (Figure 1). ${ }^{2}$ Above that income level, reported minimum-needed food spending increased as incomes rose up to about 42 percent of the poverty threshold for households with incomes seven times the poverty line. Usual food spending, on the other hand, increased more or less consistently from about 27 percent of the poverty threshold at low levels of income to about 54 percent of the poverty threshold for households with incomes of seven times the poverty line. The higher-than-expected food spending and minimum-needed food spending in the lowest income category in the CPS reflects the mixed composition of this income group. It includes some households with temporarily low income whose consumption patterns reflect longer term income.

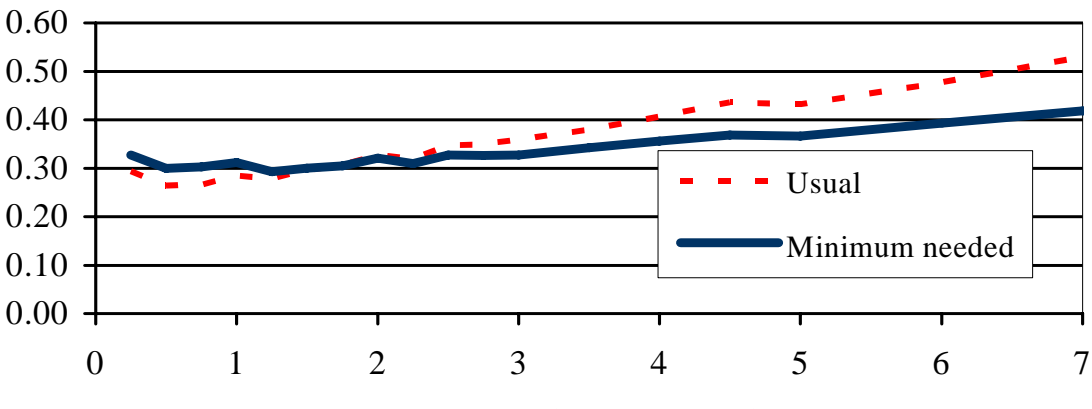

Income (relative to poverty line)

FIGURE 1. Mean Reported Usual Food Spending and Minimum-Needed Food Spending, by Income (2000-2002)

\footnotetext{
${ }^{1}$ Median values of minimum-needed food spending and usual food spending in each income range were about 5 percentage points lower than the means. This relationship was very consistent so that the associations with income and the relationships between minimum-needed and usual food spending were essentially identical whether they were assessed using mean or median measures.

${ }^{2}$ The poverty thresholds were originally specified at a level three times the amount households were thought to require to purchase an "economy food plan." Subsequent to original specification, the poverty thresholds have been adjusted only for CPI inflation. It is interesting, then, that 40 years later, the minimum needed food spending reported by low-income households, on average, is not far from 33 percent of the poverty threshold. However, usual food spending reported by households with incomes near the poverty line averaged only about 29 percent of the poverty threshold.
} 


\subsection{Cost-of-Enough-Food Indices for Basic CPS Areas}

Based on these findings, we calculated two cost-of-enough-food indices for each of 470 geographic areas identified in the CPS. These areas, hereafter referred to as basic CPS areas, are the smallest geographic areas that are identified for all respondents in the CPS. The basic CPS areas are described in more detail following the descriptions of the two indices.

Cost-of-Enough-Food Index \#1 is based directly on reported minimum-needed food spending, with the estimation sample restricted to households with incomes less than three times the poverty line. The Cost-of-Enough-Food Index \#1 for a basic CPS area was calculated as the ratio of the mean of this variable within the area to the national mean.

Cost-of-Enough-Food Index \#2 is based on income-adjusted minimum-needed food spending using an estimation sample of households with incomes up to five times the poverty line. It was considered essential to adjust for income when including households with incomes higher than three times the poverty line. The higher minimum-needed food spending reported by these households would otherwise artifactually increase the index in higher income areas. We first fitted an ordinary least-squares regression, at the national level, of reported minimum needed food spending on income. Income (as a ratio to the poverty threshold) was entered as a quadratic (income and income squared) plus a dummy variable for income less than 0.5 times the poverty line (Table 1). All coefficients were statistically significant, but the $\mathrm{R}^{2}$ was only $.018(\mathrm{~F}=675.6$ with $\mathrm{df}=3)$. This was not surprising considering that we had observed only a weak association with income across most of the low-income range and that the minimum needed food spending is affected by many factors other than income and is probably reported with substantial error. The income-adjusted minimum-needed food spending for each household was calculated by adding the household's residual from this regression to the mean "minimum-needed food spending" for the estimation sample. Cost-of-Enough-Food Index \#2 for a basic CPS area was then calculated as the mean of the income-adjusted minimum-needed food spending for households in the area. ${ }^{3}$

Adjusting reported minimum-needed food spending for income allowed the use of a larger sample to estimate Cost-of-Enough-Food Index \#2, thus providing more precise estimates than for Index \#1. This was particularly important for areas with small populations such as nonmetro areas of some states. Index \#1 may exaggerate differences in food costs across areas because higher-income households have slightly higher expectations of an adequate diet. On the other hand, Index \#2 may understate differences in food costs across areas. Some of the measured positive association between income and

\footnotetext{
${ }^{3}$ The initial calculations of both food cost indices were based on a national mean of 1.0 within the estimation samples (weighted by household supplement weights). Bases of both indices were adjusted finally to a population-weighted national mean of 1.0. These very small adjustments were accomplished by multiplying the indices for all basic CPS areas by a constant.
} 
The Review of Regional Studies, Vol. 35, No. 3, 2005, pp. 291-310

TABLE 1

Regression Results: Reported Minimum-Needed Food Spending Regressed on Income for Households with Reported Incomes Less Than

Five Times the Household's Poverty Threshold

\begin{tabular}{lccc}
\hline & & Standard & \\
Variable & Coefficient & Error & $\operatorname{Pr}>|\mathrm{t}|$ \\
\hline Intercept & .2988 & .0024 & \\
Income-to-poverty ratio & .0086 & .0020 & $<.0001$ \\
Square of income-to-poverty ratio & .0018 & .0004 & $<.0001$ \\
Dummy for income less than 0.5 times poverty threshold & .0149 & .0029 & $<.0001$ \\
\hline Number of cases 109,197 & & & \\
$\mathrm{R}^{2}=.018 ; \mathrm{F}=$ 675.6 with df $=3$ & & & \\
\hline
\end{tabular}

reported minimum-needed food spending probably results from areas with high food prices (and, likely, higher costs of living in general) being less attractive to low-income households. Thus, when used to compare the cost-of-enough-food between two areas, the two indices probably bracket an unbiased comparison-that is, the comparison that would be reported by a single household, with constant income, living successively in the two areas. We will consider both indices in making inter-area comparisons. We calculated several additional indices - described later in this section - to test the robustness of the inter-area comparisons to various assumptions and methodological approaches.

The basic CPS areas for which the two cost-of-enough-food indices were calculated were defined by cross-classifying households by three CPS variables: GESTCEN $\times$ GEMSA $\times$ GEMSAST. GESTCEN uniquely identifies each state and the District of Columbia. GEMSA uniquely identifies most metropolitan statistical areas (MSAs), with a residual category that includes nonmetro areas and non-identified MSAs. GEMSAST identifies the following categories: MSA Central City/Balance MSA/Not in MSA/Not Identified.

\subsection{Comparisons of Cost-of-Enough-Food Indices across Larger Geographical Areas}

The two cost-of-enough-food indices were compared between households living in metro and nonmetro areas at the national level, for each Census Region, for each Census Division, and for each state. The index for an area that comprised more than one basic CPS area was calculated as the weighted mean of the indices of its constituent basic CPS areas, using full-population weights. That is, each basic CPS area was weighted by the sum of household supplement weights for all households in the area (average for the four surveys), not just for the low-income households that had been used to estimate the foodcost indices.

Standard deviations of estimated cost-of-enough-food indices were calculated based on variances within each basic CPS area. The within-basic-CPS-area sums of squares were aggregated to the larger geographical areas, and variances were calculated for these 
areas based on the number of cases in the estimation sample. A design factor of 1.6 was assumed for multiple-state areas and a design factor of 1.2 was assumed for single states and for metro and nonmetro areas within a single state. ${ }^{4}$

\subsection{Sample Size and Exclusions}

The combined samples of the CPS-FSS for the four surveys was 172,890 households. The entire sample was used to calulate population weights for the basic CPS areas. The sample used to calculate the cost-of-enough-food indices excluded households that did not answer the series on minimum needed food spending (6.9 percent), did not report income (9.6 percent), or reported minimum-needed food spending less than 5 percent or greater than 100 percent of the poverty threshold (5.7 percent of otherwise eligible households). These very low or very high values of minimum-needed food spending appeared to be either data errors or to represent idiosyncratic food spending situations. The resulting estimation samples consisted of 66,136 households with incomes less than three times the poverty line for calculating Index \#1 and 109,216 households with incomes less than five times the poverty line for calculating Index \#2.

\subsection{Robustness Checks}

We calculated alternative indices corresponding to Index \#1 and Index \#2 but based on medians rather than means across households within a basic CPS area (analysis not shown). Medians would be more robust than means to the influence of outliers in reported minimum food spending. The median-based indices were highly correlated with the mean-based indices. The Pearson correlation coefficient was .92 for Index \#1 and .89 for Index \#2 across the 470 basic CPS areas and .99 for both indices across states.

If the poverty thresholds do not correctly adjust for differences in food needs by households of difference compositions, then the cost-of-enough-food indices could be biased between regions that differed in their mix of household compositions. To assess this possible distortion, we calculated an alternative income-adjusted food cost index (analysis not shown). In the regression adjustment for Index \#2, the poverty threshold was used to norm both minimum-needed food spending and household income. In the regression adjustment for the alternative index, both minimum-needed food spending and income were entered in dollars, not normalized by the poverty threshold, and 23 independent variables were added to the model to describe the number and gender of adults and the number and ages of children in the household. This index was very highly correlated with Index \#2. The Pearson correlation coefficient between the two indices across the 470 basic CPS areas was .97, and across states it was .99 . The variances of the two

\footnotetext{
${ }^{4}$ These design factors are consistent with earlier research based on the CPS-FSS. As a check on these design factors, we also calculated alternative variance estimates using a jackknife procedure based on the "month-in-sample" rotation structure of the CPS. The jackknife estimates were generally consistent with those based on the aggregated within-basic-CPS-area sums of squares with the design factors as specified.
} 
measures across the 470 basic CPS areas were also essentially identical. These findings indicate that norming minimum-needed food spending and income by the poverty threshold did not introduce any substantial estimation error for the index among the basic CPS areas.

Social and cultural factors could influence perceptions of what constitutes "enough food" and thereby affect the cost-of-enough-food indices. If such factors are systematically related to rural versus urban residence or to state of residence, they could bias the comparisons or primary interest in this study. It was not possible to fully account for such factors in our analysis, but we adjusted for them to the extent possible given the data available in the CPS-FSS. To do so, we calculated an index using the same methodology as for Index \#2, except that we included in the regression equation a set of dummy variables representing race (four categories), Hispanic ethnicity (two categories), education (five categories), and respondent's age (six categories). Although the regression coefficients on all of the socio-cultural variables were significant, the $\mathrm{R}^{2}$ increased only modestly (to .030) and the "socio-cultural adjusted" index was highly correlated with Index \#2 across the 470 basic CPS areas $(r=.99)$ and across states $(r=.99)$. The socio-cultural adjusted index had slightly smaller variance (4 percent smaller) than Index \#2, but the effects of this adjustment on the main findings of the study were slight.

\subsection{Cost-of-Enough-Food Indices Compared with ACCRA Grocery Price Index}

As a check on external validity of the cost-of-enough-food indices, we compared them with grocery price information from the American Chamber of Commerce Researchers Association (ACCRA). ACCRA provides cost of living comparisons for a large number of cities using an approach similar to that used by the Bureau of Labor Statistics to calculate the consumer price index, except that ACCRA price comparisons are across geographic space rather than across time. We expected the "grocery items" component of the ACCRA index to be positively correlated with our cost-of-enough-food indices across cities. Several factors, however, would moderate this correlation. The ACCRA index is purely a price index, while our cost-of-enough-food indices reflect other factors, as discussed above, in addition to food prices. The ACCRA weighting of prices reflects consumption patterns of middle management, while our indices reflect those of lower-income households. The ACCRA index excludes the cost of food away from home, which is included in our indices. ACCRA sampling for many metro areas is small, may not be adequately representative, and is not weighted to facilitate aggregation of sampling points to the MSA level.

Notwithstanding these limitations, we expect at least a modest correlation between the ACCRA grocery price index and our cost-of-enough-food indices. To assess this association, we compared our indices, calculated at the MSA level, with unweighted means of the ACCRA indices (data for calendar year 2000) for cities within each MSA. Across the 171 MSAs that were common to the two data sources, correlations between the ACCRA index and our indices were positive and statistically significant, but of modest strength. Unweighted Pearson correlation coefficients were .38 for Index \#1 and 
.35 for Index \#2. Weighted by MSA population (based on CPS), correlation coeffients were .60 and .62, respectively. Correlations were somewhat stronger among the 35 largest MSAs (those with CPS-FSS estimation samples of 500 or larger): $r=.62$ unweighted and .73 weighted for both of our indices. Whether the stronger correlation for larger MSAs is due to better estimation of our indices or better estimation of the ACCRA index is not known.

\section{FINDINGS}

In general, households in nonmetro areas report that they can meet their basic food needs at a lower cost than households in metro areas. At the national level, Cost-ofEnough-Food Index \#1 was 0.89 in nonmetro areas-14 percent below the metro average of 1.03 (Table 2). Corresponding values for Index \#2 were 0.91 and 1.02, a difference of 11 percent. Both indices were lower in nonmetro than in metro areas in every Census Region and in every Census Division, and these differences were all statistically significant. Based on Index \#2, the nonmetro-metro difference was largest in the Middle Atlantic Census Division, where food costs were 15 percent lower in nonmetro than in metro areas (0.91 compared with 1.07). The smallest differences were the West South Central and Mountain Census Divisions, where nonmetro food costs were 5 percent below metro costs (0.95 compared with 1.00 in West South Central and 0.94 compared with 0.99 in Mountain).

As expected, the regression-adjusted Index \#2 indicated smaller nonmetro-metro differences than Index \#1. We expect that these are lower and upper bounds of an unbiased comparison. Which index more nearly approximates an unbiased comparison depends on the extent to which the higher minimum-needed food spending reported by households with higher incomes (within the low-income range) is due to their higher expectations of an acceptable diet, and the extent to which it is due to de facto higher food prices in the areas where higher income households live. Also as expected, given the larger estimation sample size, the standard errors were smaller for Index \#2 estimates than for Index \#1 estimates. These patterns were consistent for all regions and Census Divisions. The two indices tell a consistent story, however, about the nonmetro-metro differences, and we will give primary attention to Index \#2 in the further discussion.

The cost-of-enough-food in both nonmetro and metro areas varied substantially across Census Regions and Divisions. Consistent with estimates by Blisard, Jayachandran, and Cromartie (2003, appendix table 1) based on Consumer Expenditure Survey data, the cost-of-enough-food overall (nonmetro and metro combined) was lowest in the Midwest and South Census Regions. Among the nine Census Divisions, both nonmetro and metro area indices were lowest in the West North Central (0.83 nonmetro and 0.92 metro) and highest in the Pacific Census Division (0.98 nonmetro and 1.08 metro). 
The Review of Regional Studies, Vol. 35, No. 3, 2005, pp. 291-310

TABLE 2

Cost-of-Enough-Food Indices by Census Region, Census Division, and Metropolitan Residence Status (standard errors in parentheses)

\begin{tabular}{|c|c|c|c|c|c|c|}
\hline \multirow[b]{2}{*}{ Region } & \multicolumn{3}{|c|}{$\begin{array}{l}\text { Cost-of-Enough-Food } \\
\text { Index } \# 1^{\mathrm{a}}\end{array}$} & \multicolumn{3}{|c|}{$\begin{array}{l}\text { Cost-of-Enough-Food } \\
\text { Index } \# 2^{\mathrm{b}}\end{array}$} \\
\hline & $\begin{array}{l}\text { Non- } \\
\text { metro }\end{array}$ & Metro & All & $\begin{array}{l}\text { Non- } \\
\text { metro }\end{array}$ & Metro & All \\
\hline United States & $\begin{array}{l}.89 \\
(.0040)\end{array}$ & $\begin{array}{l}1.03 \\
(.0031)\end{array}$ & $\begin{array}{l}1.00 \\
(.0025)\end{array}$ & $\begin{array}{l}.91 \\
(.0032)\end{array}$ & $\begin{array}{l}1.02 \\
(.0023)\end{array}$ & $\begin{array}{l}1.00 \\
(.0019)\end{array}$ \\
\hline Northeast Census Region & $\begin{array}{l}.91 \\
(.0106)\end{array}$ & $\begin{array}{l}1.06 \\
(.0068)\end{array}$ & $\begin{array}{l}1.04 \\
(.0059)\end{array}$ & $\begin{array}{l}.92 \\
(.0084)\end{array}$ & $\begin{array}{l}1.06 \\
(.0049)\end{array}$ & $\begin{array}{l}1.04 \\
(.0043)\end{array}$ \\
\hline $\begin{array}{l}\text { New England (ME, NH, VT, } \\
\text { MA, RI, CT) }\end{array}$ & $\begin{array}{l}.93 \\
(.0120)\end{array}$ & $\begin{array}{l}1.04 \\
(.0099)\end{array}$ & $\begin{array}{l}1.02 \\
(.0079)\end{array}$ & $\begin{array}{l}.94 \\
(.0095)\end{array}$ & $\begin{array}{l}1.05 \\
(.0071)\end{array}$ & $\begin{array}{l}1.03 \\
(.0058)\end{array}$ \\
\hline Middle Atlantic (NY, NJ, PA) & $\begin{array}{l}.90 \\
(.0210)\end{array}$ & $\begin{array}{l}1.07 \\
(.0091)\end{array}$ & $\begin{array}{l}1.05 \\
(.0084)\end{array}$ & $\begin{array}{l}.91 \\
(.0168)\end{array}$ & $\begin{array}{l}1.07 \\
(.0067)\end{array}$ & $\begin{array}{l}1.05 \\
(.0062)\end{array}$ \\
\hline Midwest Census Region & $\begin{array}{l}.83 \\
(.0068)\end{array}$ & $\begin{array}{l}.97 \\
(.0060)\end{array}$ & $\begin{array}{l}.93 \\
(.0046)\end{array}$ & $\begin{array}{l}.84 \\
(.0054)\end{array}$ & $\begin{array}{c}.96 \\
(.0043)\end{array}$ & $\begin{array}{l}.93 \\
(.0034)\end{array}$ \\
\hline $\begin{array}{l}\text { East North Central (OH, IN, } \\
\text { IL, MI, WI) }\end{array}$ & $\begin{array}{l}.83 \\
(.0129)\end{array}$ & $\begin{array}{l}.98 \\
(.0077)\end{array}$ & $\begin{array}{l}.95 \\
(.0067)\end{array}$ & $\begin{array}{c}.84 \\
(.0101)\end{array}$ & $\begin{array}{c}.97 \\
(.0056)\end{array}$ & $\begin{array}{l}.94 \\
(.0049)\end{array}$ \\
\hline $\begin{array}{l}\text { West North Central (MN, IA, } \\
\text { MO, ND, SD, NE, KS) }\end{array}$ & $\begin{array}{l}.84 \\
(.0080)\end{array}$ & $\begin{array}{c}.94 \\
(.0096)\end{array}$ & $\begin{array}{l}.90 \\
(.0063)\end{array}$ & $\begin{array}{l}.83 \\
(.0063)\end{array}$ & $\begin{array}{c}.92 \\
(.0067)\end{array}$ & $\begin{array}{l}.89 \\
(.0047)\end{array}$ \\
\hline South Census Region & $\begin{array}{l}.92 \\
(.0073)\end{array}$ & $\begin{array}{l}1.01 \\
(.0054)\end{array}$ & $\begin{array}{l}.99 \\
(.0044)\end{array}$ & $\begin{array}{l}.94 \\
(.0060)\end{array}$ & $\begin{array}{l}1.01 \\
(.0041)\end{array}$ & $\begin{array}{l}1.00 \\
(.0034)\end{array}$ \\
\hline $\begin{array}{l}\text { South Atlantic (DE, MD, DC, } \\
\text { VA, WV, NC, SC, GA, FL) }\end{array}$ & $\begin{array}{l}.93 \\
(.0119)\end{array}$ & $\begin{array}{l}1.02 \\
(.0071)\end{array}$ & $\begin{array}{l}1.01 \\
(.0062)\end{array}$ & $\begin{array}{l}.95 \\
(.0098)\end{array}$ & $\begin{array}{l}1.02 \\
(.0053)\end{array}$ & $\begin{array}{l}1.01 \\
(.0047)\end{array}$ \\
\hline $\begin{array}{l}\text { East South Central (KY, TN, } \\
\text { AL, MS) }\end{array}$ & $\begin{array}{l}.89 \\
(.0130)\end{array}$ & $\begin{array}{l}.99 \\
(.0141)\end{array}$ & $\begin{array}{l}.95 \\
(.0096)\end{array}$ & $\begin{array}{l}.92 \\
(.0106)\end{array}$ & $\begin{array}{l}.99 \\
(.0104)\end{array}$ & $\begin{array}{l}.96 \\
(.0075)\end{array}$ \\
\hline $\begin{array}{l}\text { West South Central (AR, LA, } \\
\text { OK, TX) }\end{array}$ & $\begin{array}{l}.92 \\
(.0131)\end{array}$ & $\begin{array}{l}1.00 \\
(.0101)\end{array}$ & $\begin{array}{l}.98 \\
(.0081)\end{array}$ & $\begin{array}{l}.95 \\
(.0111)\end{array}$ & $\begin{array}{l}1.00 \\
(.0079)\end{array}$ & $\begin{array}{l}.99 \\
(.0065)\end{array}$ \\
\hline West Census Region & $\begin{array}{l}.95 \\
(.0090)\end{array}$ & $\begin{array}{l}1.06 \\
(.0065)\end{array}$ & $\begin{array}{l}1.05 \\
(.0053)\end{array}$ & $\begin{array}{l}.96 \\
(.0071)\end{array}$ & $\begin{array}{l}1.06 \\
(.0049)\end{array}$ & $\begin{array}{l}1.04 \\
(.0041)\end{array}$ \\
\hline $\begin{array}{l}\text { Mountain (MT, ID, WY, CO, } \\
\text { NM, AZ, UT, NV) }\end{array}$ & $\begin{array}{l}.93 \\
(.0103)\end{array}$ & $\begin{array}{l}.99 \\
(.0094)\end{array}$ & $\begin{array}{l}.98 \\
(.0070)\end{array}$ & $\begin{array}{l}.94 \\
(.0081)\end{array}$ & $\begin{array}{l}.99 \\
(.0070)\end{array}$ & $\begin{array}{l}.98 \\
(.0054)\end{array}$ \\
\hline $\begin{array}{l}\text { Pacific (WA, OR, CA, AK, } \\
\text { HI) }\end{array}$ & $\begin{array}{l}.97 \\
(.0180)\end{array}$ & $\begin{array}{l}1.09 \\
(.0089)\end{array}$ & $\begin{array}{l}1.08 \\
(.0080)\end{array}$ & $\begin{array}{l}.98 \\
(.0139)\end{array}$ & $\begin{array}{l}1.08 \\
(.0066)\end{array}$ & $\begin{array}{l}1.07 \\
(.0060)\end{array}$ \\
\hline
\end{tabular}

Notes:

${ }^{a}$ Cost-of-Enough-Food Index \#1 is based on mean reported household minimum-needed food spending by households with income less than three times the poverty line.

${ }^{\mathrm{b}}$ Cost-of-Enough-Food Index \#2 is based on mean regression-adjusted household minimum-needed food spending by households with income less than five times the poverty line. Each household's reported minimum-needed food spending was adjusted based on national-level regression of reported minimumneeded food spending on annual household income. (See Table 1 for regression coefficients.)

In most states, too, the nonmetro cost-of-enough-food was lower than that in metro areas (Table 3). Estimated food costs based on Index \#2 were lower in nonmetro than in metro areas in 38 of the 46 states for which nonmetro areas are identified in the CPS, and the differences were statistically significant in 28 states. In eight states, estimated food costs were higher in nonmetro than in metro areas, but the differences were statistically significant in only three states-Alaska, Hawaii, and Idaho. 
Comparing across states (nonmetro and metro combined), the highest food costs were in Alaska (1.14), Hawaii (1.11), and California (1.11) and the lowest were in North Dakota (0.81), Nebraska (0.83), and South Dakota (0.84). For nonmetro areas of states, the highest food costs were in Hawaii (1.22), Alaska (1.18), and Florida (1.10) while the lowest were in Nebraska (0.77), Utah (0.79), Wisconsin (0.80) and North Dakota (0.80). There was more variability in food costs across states in nonmetro areas than in metro areas. For states with nonmetro areas identified in the CPS, the standard deviation of Cost-of-Enough-Food Index \#2 is 37 percent higher across nonmetro areas than metro areas. This may suggest higher variability across nonmetro areas within states as well.

Adjustment of Index \#2 for socio-cultural differences (race, Hispanic ethnicity, age, and education) reduced the nonmetro-metro differences only slightly (analysis not shown). At the national level, the nonmetro index was 0.92 for the socio-cultural adjusted index compared with 0.91 for Index \#2. Differences of about this magnitude between the socio-cultural adjusted index and Index \#2 were observed in the nonmetro areas of almost all regions, Census Divisions, and states. The difference between the two indices was negligible for metro areas overall; and differences were small and inconsistent in the metro areas of regions, Divisions, and states. In only one state (Tennessee) did a statistically significant nonmetro-metro difference in Index \#2 become statistically insignificant with the socio-cultural adjustment. Although these comparisons could account only partially for socio-cultural differences, the small size of the effects of this adjustment suggest that such differences have at most a modest effect on the cost-ofenough-food comparisons presented in Tables 2 and 3.

\section{SUMMARY AND CONCLUSIONS}

The amount households report needing to spend to just meet their food needs are generally lower in nonmetro areas than in metro areas. At the national level, the cost-ofenough-food was found to be between 11 and 14 percent lower in nonmetro areas than in metro areas, depending on the specific index used for the analysis. The cost-of-enoughfood was lower in nonmetro than in metro areas in every Census Division and in most states. Food costs also varied considerably across states in both nonmetro and metro areas.

These differences have implications for comparing income-based measures of wellbeing — such as median household income and poverty rates-between nonemetro and metro areas and across states. The correspondence between income and consumption depends substantially on the costs of goods. Housing and food are the largest expense categories for most low-income households, and housing costs have been found in previous research to also be, on average, lower in nonmetro than in metro areas. The lower costs of food and housing in nonmetro areas suggests that comparisons based on income overstate the economic disadvantage of nonmetro households compared with metro households. 
TABLE 3

Cost-of-Enough-Food Index \#2 by State and Metropolitan Residence Status

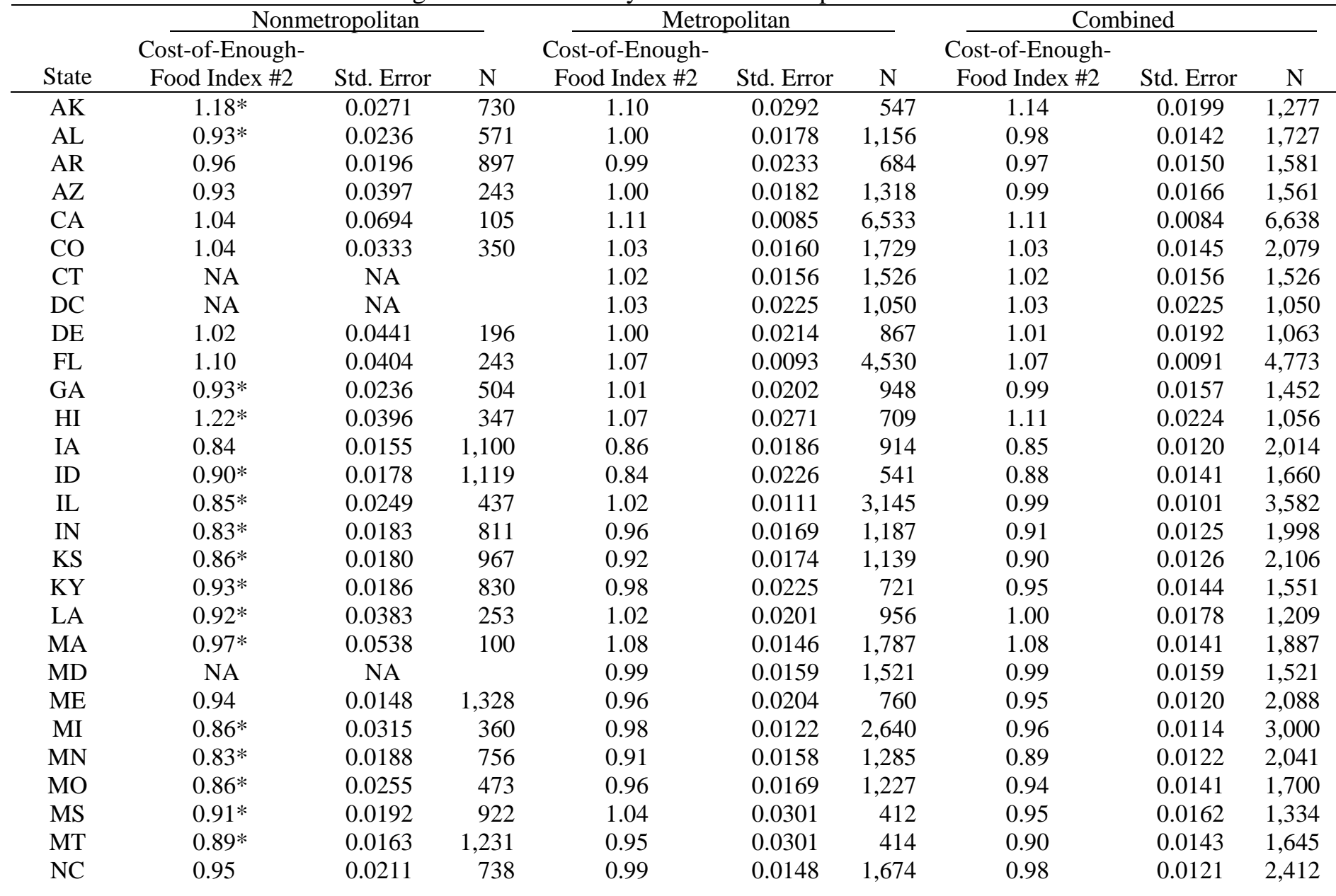




\begin{tabular}{|c|c|c|c|c|c|c|c|c|c|}
\hline \multirow[b]{2}{*}{ State } & \multicolumn{3}{|c|}{ Nonmetropolitan } & \multicolumn{3}{|c|}{ Metropolitan } & \multicolumn{3}{|c|}{ Combined } \\
\hline & $\begin{array}{l}\text { Cost-of-Enough- } \\
\text { Food Index \#2 }\end{array}$ & Std. Error & $\mathrm{N}$ & $\begin{array}{l}\text { Cost-of-Enough- } \\
\text { Food Index \#2 }\end{array}$ & Std. Error & $\mathrm{N}$ & $\begin{array}{l}\text { Cost-of-Enough- } \\
\text { Food Index \#2 }\end{array}$ & Std. Error & $\mathrm{N}$ \\
\hline ND & 0.80 & 0.0143 & 1,271 & 0.82 & 0.0164 & 948 & 0.81 & 0.0108 & 2,219 \\
\hline $\mathrm{NE}$ & $0.77 *$ & 0.0148 & 996 & 0.87 & 0.0172 & 1,132 & 0.83 & 0.0116 & 2,128 \\
\hline $\mathrm{NH}$ & $0.92 *$ & 0.0222 & 591 & 0.99 & 0.0179 & 1,063 & 0.97 & 0.0139 & 1,654 \\
\hline $\mathrm{NJ}$ & NA & NA & & 1.09 & 0.0145 & 2,232 & 1.09 & 0.0145 & 2,232 \\
\hline NM & 1.01 & 0.0270 & 624 & 0.99 & 0.0214 & 832 & 1.00 & 0.0168 & 1,456 \\
\hline NV & $0.96 *$ & 0.0331 & 322 & 1.04 & 0.0151 & 1,655 & 1.03 & 0.0138 & 1,977 \\
\hline NY & $0.91 *$ & 0.0221 & 621 & 1.10 & 0.0104 & 4,208 & 1.08 & 0.0095 & 4,829 \\
\hline $\mathrm{OH}$ & $0.88 *$ & 0.0276 & 412 & 0.96 & 0.0103 & 3,277 & 0.95 & 0.0096 & 3,689 \\
\hline $\mathrm{OK}$ & 0.95 & 0.0236 & 605 & 0.98 & 0.0193 & 1,020 & 0.97 & 0.0150 & 1,625 \\
\hline OR & 0.91 & 0.0273 & 458 & 0.96 & 0.0168 & 1,231 & 0.94 & 0.0143 & 1,689 \\
\hline PA & $0.91 *$ & 0.0258 & 489 & 0.98 & 0.0107 & 3,414 & 0.97 & 0.0099 & 3,903 \\
\hline RI & NA & NA & & 1.00 & 0.0138 & 1,779 & 1.00 & 0.0138 & 1,779 \\
\hline SC & $0.93^{*}$ & 0.0302 & 389 & 1.01 & 0.0173 & 1,093 & 0.99 & 0.0150 & 1,482 \\
\hline SD & $0.81 *$ & 0.0140 & 1,343 & 0.89 & 0.0203 & 797 & 0.84 & 0.0116 & 2,140 \\
\hline $\mathrm{TN}$ & $0.91 *$ & 0.0262 & 448 & 0.98 & 0.0185 & 986 & 0.96 & 0.0151 & 1,434 \\
\hline $\mathrm{TX}$ & $0.94^{*}$ & 0.0184 & 936 & 1.00 & 0.0105 & 3,659 & 0.99 & 0.0092 & 4,595 \\
\hline UT & $0.79 *$ & 0.0260 & 317 & 0.89 & 0.0162 & 1,273 & 0.87 & 0.0140 & 1,590 \\
\hline VA & $0.88 *$ & 0.0279 & 423 & 1.02 & 0.0177 & 1,257 & 0.99 & 0.0150 & 1,680 \\
\hline VT & $0.93^{*}$ & 0.0158 & 1,272 & 0.99 & 0.0262 & 449 & 0.95 & 0.0135 & 1,721 \\
\hline WA & 0.92 & 0.0275 & 491 & 0.96 & 0.0166 & 1,406 & 0.95 & 0.0142 & 1,897 \\
\hline WI & $0.80 *$ & 0.0177 & 787 & 0.87 & 0.0146 & 1,487 & 0.85 & 0.0114 & 2,274 \\
\hline WV & 1.00 & 0.0196 & 947 & 0.97 & 0.0206 & 906 & 0.98 & 0.0142 & 1,853 \\
\hline WY & $0.92 *$ & 0.0165 & 1,281 & 1.03 & 0.0278 & 558 & 0.96 & 0.0142 & 1,839 \\
\hline
\end{tabular}


It is possible that the nonmetro-metro differences in costs of housing and food are partially offset by higher costs of other goods and services in nonmetro areas. Transportation, for example, may be more costly in nonmetro areas. (The cost-of-enough-food indices do not take account of the cost - in time and money-of transportation for food shopping.) However, the nonmetro-metro differences in costs of food and housing are consistent with differences in overall cost of living - 16 percent lower in nonmetro areas - estimated by Nord (2000). This suggests that if costs of transportation and other goods and services are higher in nonmetro than in metro areas, they only partially offset the lower costs of food and housing.

It is likely that food costs vary substantially across the rural landscape within some states. Thus, notwithstanding the generally lower food costs in nonmetro areas, food costs may be much higher in some rural areas-especially areas that are remote from urban centers, have low population density, and are poorly served by transport infrastructure. The CPS-FSS data cannot reflect these differences within nonmetro areas below the state level. Such a pattern may be suggested by the general remoteness of rural parts of the three states in which the cost-of-enough-food indices were higher (with differences statistically significant) in nonmetro than in metro areas: Hawaii, Alaska, and Idaho. On the other hand, across all states, the association between the nonmetro-metro food-cost differential and the proportion of nonmetro population in the most remote category of nonmetro counties was negligible (and negative in sign; analysis not shown).

In some states, cost-of-enough-food indices were similar in nonmetro and metro areas, while in other states differences were large. Further research might usefully explore the extent to which these state-to-state differences are associated with differences in rural settlement patterns, rural infrastructure, rural economic structure, average distance from major urban centers, and other conditions in rural areas.

Further research is needed to assess the relative contributions of price differences, social expectations, and other factors to the nonmetro-metro and other inter-area differences in the cost-of-enough-food. Differences in the proportion of food budgets spent for food away from home may also play an important role in inter-area differences in the cost of food, and CPS-FSS data on food spending for at-home consumption and for food away from home could help address this question.

The cost-of-enough-food indices provide insight into regional and nonmetro-metro differences in the extent to which food stamp benefits-which are based on average national food prices-are sufficient to meet the food needs of families that depend upon them. Although the differences between areas in the cost of enough food suggest that some adjustment of food stamp benefits for local food costs might be desirable, it is not clear that such an adjustment is feasible. The cost-of-enough-food indices do not by themselves provide an adequate basis for adjusting food stamp benefits; such an adjustment would need to be based on a more objective standard such as the price differences of food items in the Thrifty Food Plan. However, the extent of differences across geographic areas might suggest basing maximum benefits nationwide on a higher percentile 
of the national distribution of food prices rather than on average national food prices. The cost-of-enough-food index may also inform state and city decisions about whether to supplement food stamp benefits.

The CPS-FSS data on food spending and minimum-needed food spending almost certainly do not provide an adequate statistical basis to adjust the official poverty thresholds. They can, nevertheless, improve research-based information about the extent to which rural households are more or less disadvantaged economically than their urban counterparts. Poverty thresholds used in research applications can be adjusted for costs of housing, based on available cost-of-housing data, and for costs of food based on the statistics provided in this paper. Cost-of-food adjustments based on the methods described in this paper can be made separately for metro central city, metro outside of central city, and nonmetro components of each state. ${ }^{5}$

\section{REFERENCES}

Beale, C., 2004. "Anatomy of Nonmetro High-Poverty Areas: Common in Plight, Distinctive in Nature," Amber Waves 2(1), 20-27. U.S. Department of Agriculture, Economic Research Service: Washington, D.C.

Berndt, E., D. Cutler, R. Frank, Z. Grilliches, J. Newhouse, and J. Triplett, 1998. "Price Indexes for Medical Care Goods and Services: An Overview of Measurement Issues,” NBER Working Paper 6817. National Bureau of Economic Research: New York.

Blisard, N., J.N. Variyam, and J. Cromartie, 2003. Food Expenditures by U.S. Households: Looking Ahead to 2020, Agricultural Economic Report No. 821. U.S. Department of Agriculture, Economic Research Service: Washington, D.C.

Chung, C. and S.L. Myers, Jr., 1999. "Do the Poor Pay More for Food? An Analysis of Grocery Store Availability and Food Price Disparities," Journal of Consumer Affairs 33, 276-296.

Citro, C.F. and R.T. Michael (Eds.), 1995. Measuring Poverty: A New Approach. National Academy Press: Washington, D.C.

Davis, D.E. and E.S. Leibtag, 2004. Explaining Interstate Variation in Average Monthly WIC Food Package Costs: The Role of Food Prices, Caseload Composition, and Cost-Containment Practices, Electronic Food Assistance and Nutrition Research Report. U.S. Department of Agriculture, Economic Research Service: Washington, D.C.

Economic Research Service, 1976. The Measure of Poverty. Technical Paper XV: Analytical Support for Cost-of-Living Differentials in the Poverty Thresholds. U.S. Government Printing Office: Washington, D.C.

Finke, M.S., W.S. Chern, and J.J. Fox, 1997. "Do the Urban Poor Pay More for Food? Issues in Measurement," Advancing the Consumer Interest 9, 13-17.

Fisher, I., 1927. The Making of Index Numbers (Third Edition). Sentry Press: New York.

${ }^{5}$ The authors can also provide the indices calculated for metropolitan statistical areas that are identified in the CPS. 
Frankel, D. and E. Gould, 2001. "The Retail Price of Inequality," Journal of Urban Economics 49, 219-239.

Government Accounting Office, 1995. Poverty Measurement: Adjusting for Geographic Cost-of-Living Difference, GAO/GGD-95-64. U.S. General Accounting Office: Washington, D.C.

Hamrick, K. (Ed.), 2005. Rural America at a Glance, 2005, Economic Information Bulletin No. EIB-4. U.S. Department of Agriculture, Economic Research Service: Washington, D.C.

Hayes, L., 2000. "Do the Poor Pay More? An Empirical Investigation of Price Dispersion in Food Retailing," Industrial Relations Section Working Paper No.446. Princeton University: Princeton, NJ.

Hill, P. (Ed.), 2004. Consumer Price Index Manual: Theory and Practice. International Labour Office: Geneva, Switzerland.

Jolliffe, D., 2003. Comparisons of Metropolitan-Nonmetropolitan Poverty During the 1990s, Rural Development Research Report No. RDRR96. U.S. Department of Agriculture, Economic Research Service: Washington, D.C.

Kaufman, P.R., J.M. MacDonald, S.M. Lutz, and D.M. Smallwood, 1997. Do the Poor Pay More for Food? Item Selection and Price Differences Affect Low-Income Household Food Costs, Agricultural Economic Report No. 759. U.S. Department of Agriculture, Economic Research Service: Washington, D.C.

King, R.P., E.S. Leibtag, and A. Behl, 2004. Supermarket Characteristics and Operating Costs in Low-Income Areas, Agricultural Economic Report No. 839. U.S. Department of Agriculture, Economic Research Service: Washington, D.C.

Leibtag, E.S. and P.R. Kaufman, 2003. Exploring Food Purchase Behavior of LowIncome Households: How Do They Economize? Agriculture Information Bulletin No. 747-07. U.S. Department of Agriculture, Economic Research Service: Washington, D.C.

Nord, M., 2000. "Does It Cost Less to Live in Rural Areas? Evidence from New Data on Food Security and Hunger,” Rural Sociology 65, 104-125.

Nord, M. and P. Cook, 1995. Measuring Poverty: Do the Proposed Revisions of the Poverty Measure Matter for Rural America? ERS Staff Paper No. 9514. U.S. Department of Agriculture, Economic Research Service: Washington, D.C. 